\title{
BARE SPOT LOCATION IN GLENOID CAVITY: COMPARISON BETWEEN ARTHROSCOPY AND CT SCAN
}

\author{
POSICIONAMENTO DO BARE SPOT NA CAVIDADE \\ GLENOIDAL: COMPARAÇÃO ENTRE ARTROSCOPIA \\ E TOMOGRAFIA COMPUTADORIZADA
}

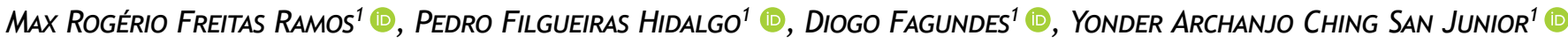 \\ 1. Universidade Federal do Estado do Rio de Janeiro, Rio de Janeiro, RJ, Brazil.
}

\section{ABSTRACT}

Objective: To assess whether Bare Spot is previously displaced by proportion (MEASURE BP-A × 1.25/MEASURE BP-P = 1). Methods: 35 patients with surgical indication for rotator cuff injury repair were evaluated. The distances from the Bare Spot to the anterior edge of the glenoid cavity (BS-A) and to the posterior edge (BS-P) were measured by arthroscopy and computed tomography with three-dimensional reconstruction of the scapula. Results: The distance from the Bare Spot to the anterior border (BS-A tc) was $11.6 \mathrm{~mm}$ with a median $12 \mathrm{~mm}$; The distance to the posterior border (BS-P tc) was on average $15.5 \mathrm{~mm}$ with a median $15 \mathrm{~mm}$. The distances from BS to anterior cavity edge measured by arthroscopy were on average (BS-A video) $12.25 \mathrm{~mm}$ with a median of $12 \mathrm{~mm}$, and from BS to posterior edge (BS-P video) $16.25 \mathrm{~mm}$ on average with median $16 \mathrm{~mm}(p<0.005)$. Conclusion: Bare Spot is displaced anteriorly at a proportion of $40 \%$ of the anterior margin and $60 \%$ of the posterior margin. Level of Evidence II - Development of diagnostic criteria on consecutive patients (with universally applied reference "gold standard").

Keywords: Joint Instability. Shoulder Joint. Pathology. Cadaver. Humans.

\section{RESUMO}

Objetivo: Avaliar in vivo se o Bare Spot (BS) se encontra deslocado anteriormente conforme a proporção (MEDIDA BP-A × 1,25/ MEDIDA BP-P = 1). Métodos: 35 pacientes com indicação cirúrgica de reparo de lesão do manguito rotador foram avaliados. As distâncias do Bare Spot à borda anterior da cavidade glenoidal (BS-A) e à borda posterior (BS-P) foram mensuradas na artroscopia e na tomografia computadorizada com reconstrução tridimensional da escápula. Resultados: A distância do BS à borda anterior (BS-A tc) foi de $11,6 \mathrm{~mm}$ com mediana de $12 \mathrm{~mm}$; a distância à borda posterior (BS-P tc) foi, em média, 15,5 mm com mediana de $15 \mathrm{~mm}$. As distâncias do BS à borda anterior da cavidade medidas na artroscopia foram, em média (BS-A vídeo), 12,25 mm com mediana de $12 \mathrm{~mm}$ e do BS à borda posterior (BS-P vídeo) de 16,25 mm, em média, com mediana de $16 \mathrm{~mm}$ ( $p<0,005)$. Conclusão: O BS se encontra deslocado anteriormente a uma proporção de $40 \%$ da margem anterior e $60 \%$ da margem posterior. Nível de Evidência II - Desenvolvimento de critérios diagnósticos em pacientes consecutivos (com padrão de referência "ouro" aplicado).

Descritores: Instabilidade Articular. Articulação do Ombro. Patologia. Cadáver. Humanos.

Citation: Ramos MRF, Hidalgo PF, Fagundes D, San YAC Jr. Bare spot location in glenoid cavity: comparison between arthroscopy and ct scan. Acta Ortop Bras. [online]. 2020;28(5):243-246. Available from URL: http://www.scielo.br/aob.

\section{INTRODUCTION}

Shoulder dislocation is a very common condition in orthopedic practice, accounting for about $2 \%$ of traumatic injuries of the upper limb, with anterior displacement being more frequent (85 to $90 \%){ }^{1}$ Recurrence of dislocation, degree of soft tissue injury, and occurrence of bone injury (in the humeral head or anterior edge of the scapular glenoid cavity) determine joint instability. ${ }^{1}$ Affecting young individuals in their productive range, this condition directly impacts the career of a professional athlete or people's ability to work. ${ }^{1,2}$ Over the centuries, anatomopathological knowledge and treatment of shoulder instability have evolved constantly. The advent of imaging and surgical technologies improved the treatment of this lesion. ${ }^{2,3}$ The recognition of the essential lesion by Bankart in 1923 has made great progress in the treatment of glenohumeral instability and serves as a central pillar to this day., ${ }^{1,2,4}$

There are several surgical techniques to treat shoulder instability; the most used one is the arthroscopic anterior-inferior glenoid lip reconstruction, but it has a high recurrence rate $(65 \%)$ in patients with bone loss greater than $25 \%$ in the anterior margin of the glenoid cavity. ${ }^{3-5}$ In these cases, bone block surgery such as the transfer of the coracoid process becomes the best option. .,6 Therefore, the precise definition of the residual bone portion in the glenoid cavity is fundamental for the correct treatment. ${ }^{3,4,6,7}$

All authors declare no potential conflict of interest related to this article. 
In 2002, Burkhart et $\mathrm{al}^{2}$ published a study on the quantification of bone loss and suggested the need to determine a constant anatomical landmark present in the glenoid cavity to define the bone loss required to produce the "inverted pear." In this article, the author defines the "Bare Spot" (BS) as an arthroscopic visualization anatomical accident, located in the center of the inferior portion of the glenoid cavity, which would serve as a parameter for measuring bone loss at the antero-inferior border. The Bare Spot equidistaria the bottom edges of lower anterior and posterior inferior cavity. Thus, during the surgery, the identification of this point would allow the reliable measurement of bone loss, which would have a direct impact on treatment. ${ }^{2-4,6,7}$

Burkhart's study motivated a number of other studies that aimed to prove the usefulness of BS, to redefine it anatomically or to refute it as a central landmark of the cavity. ${ }^{4,5,8-11}$

In our previous study, we compared the measurements of the distances from the "Bare Spot" to the anterior and posterior edges of the glenoid cavity and observed that BS is previously dislocated according to the formula (MEASURE BP-A × 1.25/MEASURE BP-P = 1). In this study, we reproduced these measurements in vivo by comparing those obtained during arthroscopy and computed tomography of the shoulder with three-dimensional reconstruction and humeral head suppression.

\section{MATERIALS AND METHODS}

The study was approved by the Ethics Committee (CAAE 54343916.2.0000.5258) and performed under the care of the Department of Orthopedics. Thirty-five patients diagnosed with rotator cuff injury with indication for surgical treatment were recruited. Patients with history of glenohumeral dislocation or instability, presence of osteophytes at the edge of the glenoid cavity, history of shoulder fractures, as well as those in which Bare Spot was not identified on computed tomography were excluded. After their consent to participate in the project, we requested a computed tomography of the shoulder to be surgically treated, with three-dimensional reconstruction of the scapula and suppression of the humeral head. With the examination, we identified BS and measured the distances from BS to the anterior and posterior edge of the glenoid cavity. The circumscription method described by Burkhart was used to define the BS positioning in relation to the cavity. Measurements were performed using the Microdata mConnect web version 2013.1.6.3 program (Figure 1).

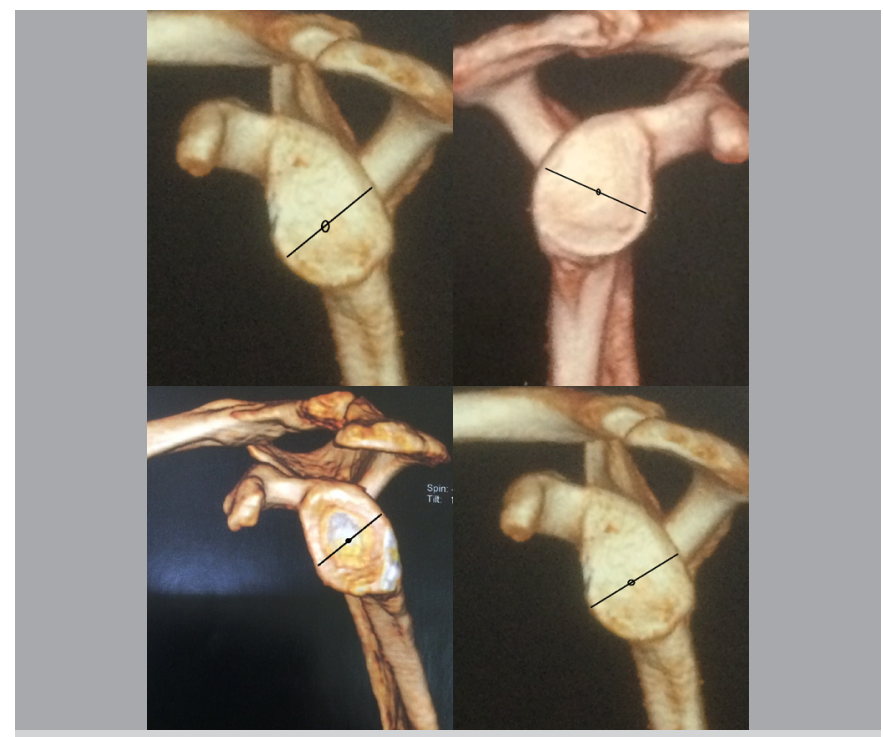

Figure 1. Measurement of the distances on the computed tomography.
The patient was then submitted to surgical treatment under arthroscopic visualization. The patients were positioned in a "beach chair," with the upper limb in $30^{\circ}$ abduction. The posterior angle of the acromion was identified. The posterior portal will be established $2 \mathrm{~cm}$ inferior and $2 \mathrm{~cm}$ medial to the vertex of the angle. Through the posterior portal we will perform arthroscopic inspection of the joint with the Smith \& Nephew ${ }^{\mathrm{R}}$ equipment $\left(4.0 \times 160.0 \mathrm{~mm} \mathrm{30^{ \circ }}\right.$ direct view arthroscope, camera Smith \& Nephew ${ }^{\mathrm{R}} 560 \mathrm{H} ; 5 \mathrm{~mm}$ fiber optic Germinicable ${ }^{\mathrm{R}}$ ).

During the procedure, we inspected the joint where the BS point was identified, and the distances from BS to the anterior and posterior edges were measured. Starting from the intraarticular environment, we established the anterior portal (inside-out) by introducing the probe through the posterior portal and progressing in a line perpendicular to the anterior edge of the glenoid cavity, in alignment with BS, tangent to the upper edge of the subscapularis tendon and progressing to the skin. Through the previous portal, a probe millimeter was introduced. With the probe tip, BS was marked, and the distances from BS to the posterior edge of the cavity (BS-P video) and from the anterior edge of the glenoid cavity to the BS (BS-A video) were measured. Measurements were performed by two independent evaluators (Figure 2).

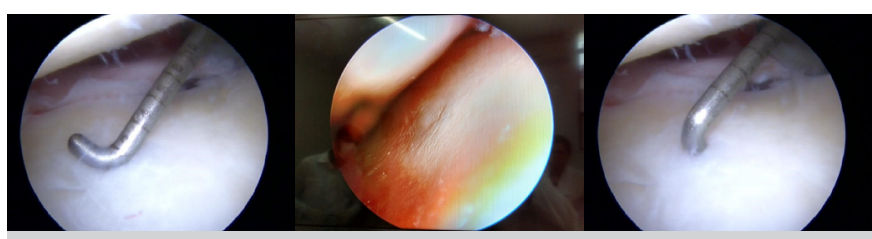

Figure 2. Measurement under arthroscopic visualization of the distances from Bare Spot to the anterior (BS-A) and posterior (BS-P) edge of the glenoid cavity.

Data were statistically analyzed using the online physics program of Saint John's University (USA). Two t-tests - student's t-test and the Kolmogorov-Smirnov test - were used to determine the statistical correlation, which was considered relevant $p<0.05$. For statistical analysis, the software statistical openSUSE online (freeware) wessa was used. ${ }^{12}$

We will carry out the kolmogorov-smirnov test for non-pared variables, which allows us to analyze whether the two samples (of finite quantities) are similarly distributed, thus refuting the null hypothesis. The kolmogorov-smirnov test allows great sensitivity for values of a finite sample with little dispersion and is more reliable than the Anderson-Darling test for points near the median.

\section{RESULTS}

The total of 42 patients underwent arthroscopy with indication for surgical treatment of the rotator cuff injury. Of these, 7 were excluded from the study, remaining 35 patients. Bare Spot was not identified in 6 patients. One patient had osteophytes on the glenoid border. We analyzed 21 women (60\%) and 14 men (40\%). Lesions were in the dominant shoulder in 24 patients (68.57\%) and in the counter-dominant in 11 (31.42\%). Ages ranged from 40 to 65 years, with an average of 53.66 years and a median of 57 years.

Regarding the measurements obtained on tomography, the distance from the Bare Spot to the anterior border (BS-A tc) was $11.6 \mathrm{~mm}$ with a median $12 \mathrm{~mm}$; The distance of the posterior border (BS-P tc) was on average $15.5 \mathrm{~mm}$ with a median $15 \mathrm{~mm}$. The distances from Bare Spot to the anterior cavity edge measured on arthroscopy were on average (BS-A video) $12.25 \mathrm{~mm}$ with a median $12 \mathrm{~mm}$, and from BS to posterior edge (BS-P video) $16.25 \mathrm{~mm}$ on average with a median $16 \mathrm{~mm}$ (Figure 3). 


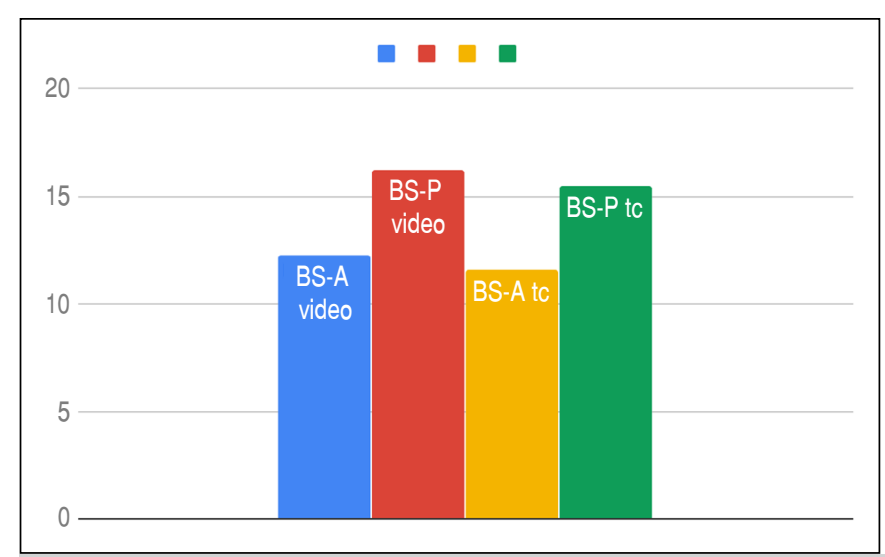

Figure 3. Result of the comparisons of measurements of the distances from Bare Spot to the anterior and posterior edge, on the computed tomography and arthroscopy. The distance from Bare Spot to the anterior edge (BS-A) was $11.6 \mathrm{~mm}$ with median $12 \mathrm{~mm}$; the distance to the posterior edge (BS-P) was on average $15.5 \mathrm{~mm}$ with median $15 \mathrm{~mm}$. The distances from BS to the anterior cavity edge measured by arthroscopy (BS-A vídeo) was on average $12.25 \mathrm{~mm}$ with median $12 \mathrm{~mm}$, and BS to the posterior edge (BS-P vídeo) was on average 16.25 with median $16 \mathrm{~mm}(\mathrm{p}<0.005)$

Comparison between measurements Bare Spot at the anterior edge by video or tomography showed no statistical difference ( $p=0.84749$ ), suggesting similarity between the measurements. Comparison of measurements Bare Spot at the posterior edge also showed no statistically significant difference ( $p=0.51755)$. By comparing the distance from Bare Spot to the anterior and posterior margins, either by video or computed tomography, we obtained a $p$-value of 0.00068234 .

\section{DISCUSSION}

Anterior shoulder instability is a relatively common clinical entity, whose prevalence has increased today, mainly due to the increasing sports demands for athletes and non-athletes. Faced with the installed lesion, there are several treatments available, each with its precise indications, advantages and disadvantages. One of the central questions in the therapeutic definition is to determine bone loss in the antero-inferior border of the glenoid cavity. In 2000, Burkhart et al. ${ }^{3}$ published a retrospective study evaluating the causes of Bankart lesion repair failure under arthroscopic visualization. In this study, the authors launched the concept of "inverted pear" and concluded that bone losses greater than $25 \%$ of the cavity diameter modify this pattern, leading to recurrence of dislocation after Bankart repair. ${ }^{13}$

The quantification of bone loss has since become fundamental to guide the therapeutic approach. In 2002, Burkhart et al. ${ }^{2}$ concluded that Bare Spot could be used as a reference for the reliable anatomical landmark of the inferior glenoid center, thus allowing the arthroscopic measurement of the anterior and posterior rays of the glenoid cavity, facilitating the quantification of bone loss. In 2004, Lo et al. ${ }^{4}$ then performed a retrospective study using the Bare Spot to identify the glenoid center during arthroscopy, thus estimating bone loss.

Several studies have attempted to replicate Burkhart's results but were unsuccessful. De Wilde et al. ${ }^{5}$ describe BS or Assaki tuber as a thinning of the subchondral bone. Vogt et al. ${ }^{6}$ describe a point of origin of the eccentric distribution of collagen fibers of the glenoid cartilage. Fealy et al. ${ }^{7}$ suggest BS is not present in immature skeletons, suggesting this point is not a constant anatomical landmark.
In 2004, Aigner et al. ${ }^{8}$ attempted to confirm Burkhart's findings by dissecting 10 cadavers. In this study, they realized that Bare Spot was not present in all specimens. In addition, they concluded that Bare Spot diverges significantly from the center of the glenoid. The distance from BS to the anterior glenoid margin $(9.7 \mathrm{~mm})$ was significantly smaller than the distance to the posterior border $(13.71 \mathrm{~m})$.

In 2006, Huysmans et al. ${ }^{9}$ analyzed 40 skeletally mature cadaver shoulder blades and found that Bare Spot was present in 35 of the 40 glenoids. They also realized there was a significant difference between the distances from the center of BS to the anterior and posterior edges of the glenoid. In this study, the average distance from BS to the anterior border was $11.04 \mathrm{~mm}$ and to the posterior was $12.96 \mathrm{~mm}$. Kralinger et al., ${ }^{10}$ in 2006, evaluated 20 scapulae using computed multislice tomography and concluded that the distance from BS to the anterior border was $9.7 \mathrm{~mm}$ (6.5 to $13.7 \mathrm{~mm}$ ), to the inferior border was $10.9 \mathrm{~mm}$ (9.1 to $13.8 \mathrm{~mm}$ ) and the posterior was $13.7 \mathrm{~mm}$ (11.3 to $19.2 \mathrm{~mm}$ ).

In 2013, Gagliardi et al. ${ }^{14}$ conducted a retrospective study by reviewing the tomographic images of 50 patients and found that the Bare Spot was not present in skeletally immature individuals under 10 years. A 14-year-old patient presented an image that could identify BS.

Miyatake et al., ${ }^{15}$ in 2014, published a series of cases evaluating the shoulder of 40 patients diagnosed with anterior glenohumeral instability and recurrent dislocations, comparing intraoperative arthroscopic measurements and computed tomography. They concluded that BS does not coincide with the center of the inferior glenoid cavity, and the estimation of bone loss under arthroscopic visualization was not accurate, suggesting that computed tomography with three-dimensional reconstruction and preoperative humerus suppression would be the most accurate way of defining bone loss. In our previous study, we looked at 20 shoulders. Measurements of the distance from the Bare Spot to the anterior and posterior edges were performed under arthroscopic visualization and open. We noticed that the Bare Spot approached the anterior edge discreetly, being the BS-P $(12.8 \mathrm{~mm})$ measurement slightly larger than the BP-A $(9.15 \mathrm{~mm})$ measurement, suggesting a more anterior BS positioning, therefore not coinciding with the center of the glenoid cavity.

In this study, we compared the measurements obtained during surgery under arthroscopy with those obtained by computed tomography of the shoulder. We did not observe significant difference between the rays measured through arthroscopy or computed tomography. When comparing the distances from the Bare Spot to the anterior and posterior edges of the glenoid cavity, we observed that the anterior displacement pattern is repeated, with the BS distance to the posterior edge slightly larger than the distance to the anterior edge. In the computed tomography measurements, the anterior radius represented $42.98 \%$ of the cavity diameter, while in arthroscopy measurements, the anterior radius represented $42.8 \%$ of the glenoid cavity diameter. Thus, the same proportion between the distances from Bare Spot to the anterior and posterior margins were observed.

The relevance of this study lies in the fact that Bare Spot has been previously displaced. Disregarding this information may induce the surgeon to overestimate bone loss, since the BS-A distance is by nature slightly smaller than BS-P. This difference may cause the specialist to adopt a more aggressive approach, opting for the transscapular osteotendinous transfer, rather than the arthroscopic labral repair technique, so a correction factor should always be used for a correct evaluation of this measurement. When associated with Hill-Sachs injury, the definition of bone loss at the anterior edge of the glenoid cavity becomes crucial. 
In cases of bipolar bone injury off-track, accurate quantification of the bone remnant in the glenoid cavity is critical for correct treatment and prevention of recurrence.

The limitations of this study were the small sample and the angle of attack of the anterior portal, which may lead to an overestimated measurement of the anterior radius, although we tried to minimize this bias through as perpendicular positioning, even if the subscapularis tendon needed to be displaced caudally.

\section{CONCLUSION}

This study suggests Bare Spot is previously displaced by a ratio of $1 / 1.25$, as previously suggested.

AUTHORS' CONTRIBUTIONS: Each author contributed individually and significantly to the development of this article. MRFR: study conception and design, data collection, analysis and interpretation, project advisor, revision; PFH: surgeries, data, tomography and statistical analysis, and writing of the article; DF: surgeries, data analysis and writing of the article; YACSJ: surgeries, data analysis, writing of the article, statistical analysis, writing of the article and critical review of its intellectual content, revision of the article and final approval of the manuscript version to be published.

\section{REFERENCES}

1. Lech $O$, Freitas JR, Piluski $P$, Severo A. Luxação recidivante do ombro: do papiro de Edwin Smith à capsuloplastia térmica. Rev Bras Ortop. 2005;40(11/12):625-37.

2. Burkhart SS, DeBeer JF, Tehrany AM, Parten PM. Quantifying glenoid bone loss arthroscopically in shoulder instability. Arthrosc. 2002;18(5):488-91.

3. Burkhart SS, DeBeer JF. Traumatic glenohumeral bone defects and their relationship to failure of arthroscopic Bankart repairs: significance of the inverted-pear glenoid and the humeral engaging Hill-Sachs lesion. Arthrosc. 2000;16(7):677-94.

4. Lo IKY, Parten PM, Burkhart SS. The inverted pear glenoid: an indicator of significant glenoid bone loss. Arthrosc. 2004;20(2):169-74.

5. De Wilde LF, Berghs BM, Audenaert E, Sys G, van Maele GO, Barbaix E. About the variability of the shape of the glenoid cavity. Surg Radiol Anat. 2004;26(1):54-9.

6. Vogt S, Eckstein F, Schön M, Putz R. Preferential direction of the collagen fibrils in the subchondral bone of the hip and shoulder joint. Ann Anat. 1999;181(2):181-9.

7. Fealy S, Rodeo SA, Dicarlo EF, O'Brien SJ. The developmental anatomy of the neonatal glenohumeral joint. J Shoulder Elbow Surg. 2000;9(3):217-22.

8. Aigner $\mathrm{F}$, Longato $\mathrm{S}$, Fritsch $\mathrm{H}$, Kralinger $\mathrm{F}$. Anatomical considerations regarding the "bare spot" of the glenoid cavity. Surg Radiol Anat. 2004;26(4):308-11.
9. Huysmans PE, Haen PS, Kidd M, Dhert WJ, Willems JW. The shape of the inferior part of the glenoid: a cadaveric study. J Shoulder Elbow Surg. 2006;15(6):759-63.

10. Kralinger $F$, Aigner $F$, Longato $S$, Rieger $M$, Wambacher $M$. Is the bare spot a consistent landmark for shoulder arthroscopy? A study of 20 embalmed glenoids with 3-dimensional computed tomographic reconstruction. Arthrosc. 2006;22(4):428-32.

11. Calandra JJ, Baker CL, Uribe J. The incidence of Hill-Sachs Lesions in initial anterior shoulder dislocations. Arthrosc. 1989;5(4):254-7.

12. Holliday IE. Kolmogorov-Smirnov Test (v1.0.4) in Free Statistics Software (v1.2.1) [Internet]. Chicago: Office for Research Development and Education; 2017 [cited 2020 June 23]. Available from: https://bit.ly/3dplqAh.

13. Shibata H, Gotoh M, Mitsui $Y$, Kai Y, Nakamura H, Kanazawa T, et al. Risk factors for shoulder re-dislocation after arthroscopic Bankart repair. J Orthop Surg Res. 2014;9(1):53.

14. Gagliardi JA, Carino M. Glenoid bare spot. Appl Radiol. 2013;10(1):29-31.

15. Miyatake K, Takeda Y, Fujii K, Takasago T, Iwame T. Validity of arthroscopic measurement of glenoid bone loss using the bare spot. Open Access J Sports Med. 2014;5:37-42. 